\title{
Coordinated and optimal voltage control for voltage regulation using firefly algorithm
}

\author{
Muhamad Najib Kamarudin, Tengku Juhana Tengku Hashim
}

Department of Electrical Power Engineering, Universiti Tenaga Nasional, Malaysia

\begin{abstract}
Article Info
Article history:

Received Jan 12, 2019

Revised Mar 18, 2019

Accepted May 13, 2019

\section{Keywords:}

Active distribution network

Decentralized voltage control

Distributed generation

Firefly algorithm

Optimal settings

ABSTRACT

The operation and control of electricity in distribution networks has faced great challenges as a large number of distributed generations (DGs) are integrated. Connection of distributed generations (DGs) in the distribution system offers advantages in terms of reducing distribution and transmission costs as well as encouraging the use of renewable energy sources. The power flow in the distribution systems is no longer moving in a single direction and this resulted the system to become as active distribution networks (ADN). One of the main problems in ADN is the voltage regulation issue which is to maintain the voltage to be within its permissible limits. Several methods of voltage control methods are available and focus is given in finding the optimal voltage control using artificial intelligence techniques. This paper presents an optimal and coordinated voltage control method while minimizing losses and voltage deviation of the network. The optimal and coordinated voltage control scheme is implemented on an IEEE 13 bus distribution network for loss and voltage deviation minimization in the networks. Firefly Algorithm (FA) which is a known heuristic optimization technique for finding the optimal solution is used in this work. The results are compared with another optimization method known as Backtracking Search Algorithm (BSA) for identifying the best setting for solving the voltage regulation problem. In order to solve the multi-objective optimization issue, the MATPOWER load flow simulation is integrated in the MATLAB environment with the optimization algorithm.
\end{abstract}

Copyright $(2019$ Institute of Advanced Engineering and Science. All rights reserved.

\section{Corresponding Author:}

Tengku Juhana Tengku Hashim,

Electrical Power Engineering Department,

Universiti Tenaga Nasional, Malaysia.

Email: juhana@uniten.edu.my

\section{INTRODUCTION}

The large-scale implementation of distributed generation (DG) in distributed systems has resulted in a conversion from the inactive arrangement, with unidirectional power flow, towards active distributed systems, with multi-directional power flow. With the presence of distributed generations (DGs), the bidirectional scheme has changed from the downstream unidirectional scheme to a more effective and active network that is called active distribution networks [1,2]. A lot of challenges occurred due to the change towards active distribution system and one of the key issues that has risen with high dispersion of renewable energy sources is voltage rise [2]. With uncertain variation of distributed generation (DG) and load, it may lead to larger voltage fluctuation thus making the voltage quality issues becoming more serious. Due to the unbalanced nature of the renewable energy sources such solar irradiance and wind energy, it can remarkably transform the system's voltage profile thus interfering with the established voltage control scheme, for example, the on-load tap changer (OLTC) [3, 4]. The problem of voltage rise is more critical when there is no demand in the system, as all the generations are exported back to the distribution networks. Since the objective is to improve the negative impact of connecting distributed generation (DG) into the system, essentially there is a need to 
develop an improved management and control plans to compromise the voltage variation problem in order to maintain the voltage not to exceed its permissible range $[5,6]$. In order to achieve the objectives of delivering good quality of power to the consumers, the task of determining the best possible technique to control voltage must be achieved.

Currently, there are various control plan which have been proposed by previous studies in order to overcome the effects of integration of distributed generation in distribution system in terms of voltage regulation. Conventionally, a distribution system required a connection of all the distributed generation units to operate in constant power factor control (PFC) mode [7-10]. In [10], the research work has proposed two local controllers for voltage profile regulations at buses where the renewable energy sources such as wind are connected. The first technique used fuzzy logic where it is based on reactive power compensation for supporting the distributed generation unit voltages. Another technique relies on the sensitivity analysis where it has resolved the problem of under voltages due to the miss-coordination between OLTC and DG local controlled. Research works in [11] has addressed the voltage regulation issue in finding the ideal tap setting of a voltage regulator by adjusting multiple feeders. Optimal voltage regulation method utilizing active and reactive power injection by using distributed generation unit was done in [12]. In another research work [13] the optimal power flow is applied in automatic power flow management of England distribution system. The outputs of distributed generation are determined by real-time optimal power flow under the thermal constraints. Metaheuristics optimization methods such as firefly algorithm (FA) and backtracking search algorithm (BSA) have been applied in this research work to find the ideal solutions for coordinated voltage control settings of three different voltage control methods in a network integrated with distributed generations. Firefly algorithm (FA) which was found in $[14,15]$ originated from the idea of flashing performance of fireflies which resulted in the occurrence of bioluminescent communication. The algorithm operates based on global communications among the fireflies. In the research work in [16] it was stated that the firefly algorithm (FA) developed by Yang in 2018 is one of the most dynamic method to solve optimization problems in power systems. According to the work in [17], FA has been able to obtain and find the overall and local optimal simultaneously and has obtained the objectives of meeting the energy load demand required by the consumers with the lowest operating costs. Previously the work in [18] demonstrated the ability of connecting capacitor in distribution network while achieving loss minimization, voltage improvement and increasing available transfer capability (ATC). The research aims at determining the placement of capacitor in 41 bus radial distribution networks by using Genetic Algorithm and it has shown that (GA) is capable to solve the allocation issues. Based on [19], FA is applied in the research work for finding the best ideal solution for time multiplier setting and time of operation of relay in the distribution system. Other than that, in [20] the human's identification techniques based on dorsal hand vein where the image of human blood is analyzed and Firefly Algorithm [FA] is implemented at the stage of identifying people. The identification is carried out by using the distance patterns between crossing of fireflies and their matching place. On the other hand, in [21], BSA has been utilized to find the optimal size and location of DGs in the distribution system, while reducing the system's losses and improve the reliability of the distribution system. BSA is called a dual-population algorithm because it uses current and historical population for solving the optimization problems. It is a simple structure where BSA does not rely on the early values of the constraints [22].

This paper presents a coordinated and optimal voltage control for voltage regulation using firefly algorithm. In this research work, Firefly algorithm (FA) was implemented on an IEEE 13-bus distribution network to determine the ideal settings of three different types of voltage control techniques of power factor, OLTC and curtailment of power generation by minimizing voltage deviation and power losses. In addition, two metaheuristics optimization of FA and BSA methods have been applied to distinguish the achievement between the two methods in finding the best optimal coordinated voltage control. The optimization codes have been tested in MATLAB in order to evaluate the objective function in reducing power losses and voltage variation.

\section{COORDINATED VOLTAGE CONTROL ALGORITHM IN DISTRIBUTION NETWORK CONNECTED WITH DGs}

As the capacity of DGs connected in the system increased, the generated power of the DG units may surpass the energy consumed by the utilities. The voltage will no longer decreases but somehow it is increasing the voltage from the substation along the feeder. It will cause high impact on the line voltage because of weak network connection of DGs to the distribution systems. Hence, the controller such OLTC and traditional controller may exceed the voltage limits. Therefore, in order to keep the voltage to maintain within the appropriate limits, the coordinated voltage control method has been introduced in this research work for obtaining the best ideal settings in the power systems. In this section, a coordinated voltage control 
was developed in this research work for find the ideal voltage control in the power system. The steps of developing the optimization codes is presented in 2.2.

\subsection{Determination of Ideal Settings of Coordinated Voltage Control Method}

A constrained nonlinear integer optimization issue has been expressed as a multi-objective optimization problem for finding the ideal settings of the OLTC, power factor for distributed generation, and the value of active power to be curtailed. The main objective in this work is to reduce the voltage deviation and power losses at the load buses. The optimization problem's fitness function is as follows:

$$
F_{\text {min }}=\gamma\left(P_{\text {loss }}\right)+\beta\left(V_{\text {dev }}\right)
$$

where $P_{\text {loss }}$ is the total power loss, $F$ is the fitness function, $\gamma$ is the coefficient factor for the sum of power losses, $V_{d e v}$ is the voltage deviation at all system buses, and $\beta$ is the coefficient factor for $V_{\text {dev }}$. The total real power losses, $P_{l o s s}$ and voltage deviation, $V_{d e v}$ are defined using the following equations:

$$
P_{\text {loss }}=\frac{P_{\text {loss } n o D G}-P_{\text {loss with } D G}}{P_{\text {loss } n o D G}}
$$

where $P_{\text {loss no DG }}$ is the total losses obtained before the connection of distributed generations (DGs) in the network, meanwhile $P_{\text {loss with } D G}$ is the total losses obtained after the distributed generation is integrated in the network.

$$
P_{\text {loss }}=\sum_{i=1}^{n} P_{\text {loss } i} i=1,2,3,4, \ldots, n
$$

where $n$ is the number of lines.

$$
V_{\text {dev }}=\sum_{i}^{n} \frac{V_{\text {iref }}-V_{i}}{V_{i}}
$$

where $V_{\text {iref }}$ is the indication of voltage at bus $i$ with the value used is 1 and $V_{i}$ is the real voltage at bus $i$.

Hence, according to the power flow equations stated above, the voltage deviation and power losses must be improved and reduced. Basically, multi-objective function techniques deliver a bunch of ideal results. Therefore, the finest optimization solution for this problem is achieved by using the total of the coefficient factor technique. This research work has assumed that the coefficient factor for the overall system power losses is 0.6 while the voltage deviation is considered to be 0.4 . The values are selected as such with the reason that the power loss reduction in distribution network will have a higher economic and technical impacts, compared to voltage deviation.

The inequality constraint is the constraint considered in the optimization problem which involved bus voltage in which the bus voltage magnitude must be kept within tolerable operation boundaries and are defined as follows:

$$
V_{\min } \leq\left|V_{i}\right| \leq V_{\max }
$$

where $V_{\min }$ is the lower bound of bus voltage limits, $V_{\max }$ is the upper bound of the voltage limits, and $\left|V_{i}\right|$ is the root-mean-square value of the $i^{\text {th }}$ bus voltage.

\subsection{Implementation of Firefly Algorithm for Finding the Ideal Settings of Coordinated Voltage Control Methods}

The optimization using Firefly algorithm (FA) technique has been chosen in this research work for solving the ideal settings of the coordinated voltage control methods in the power dispersal network connected to distributed generations (DGs). The implementation of Firefly algorithm method has been developed and simulated in MATLAB in finding the ideal settings of the coordinated voltage control selected $[23,24]$. At the same time using the Newton-Raphson load flow, the objective function in decreasing the voltage deviation and power losses is simulated in the MATLAB environment. The MATLAB software is used for solving the optimization coding which is integrated with the load flow simulation using MATPOWER. The flowchart of finding the ideal settings of voltage control in the power distribution system is shown in Figure 1. 


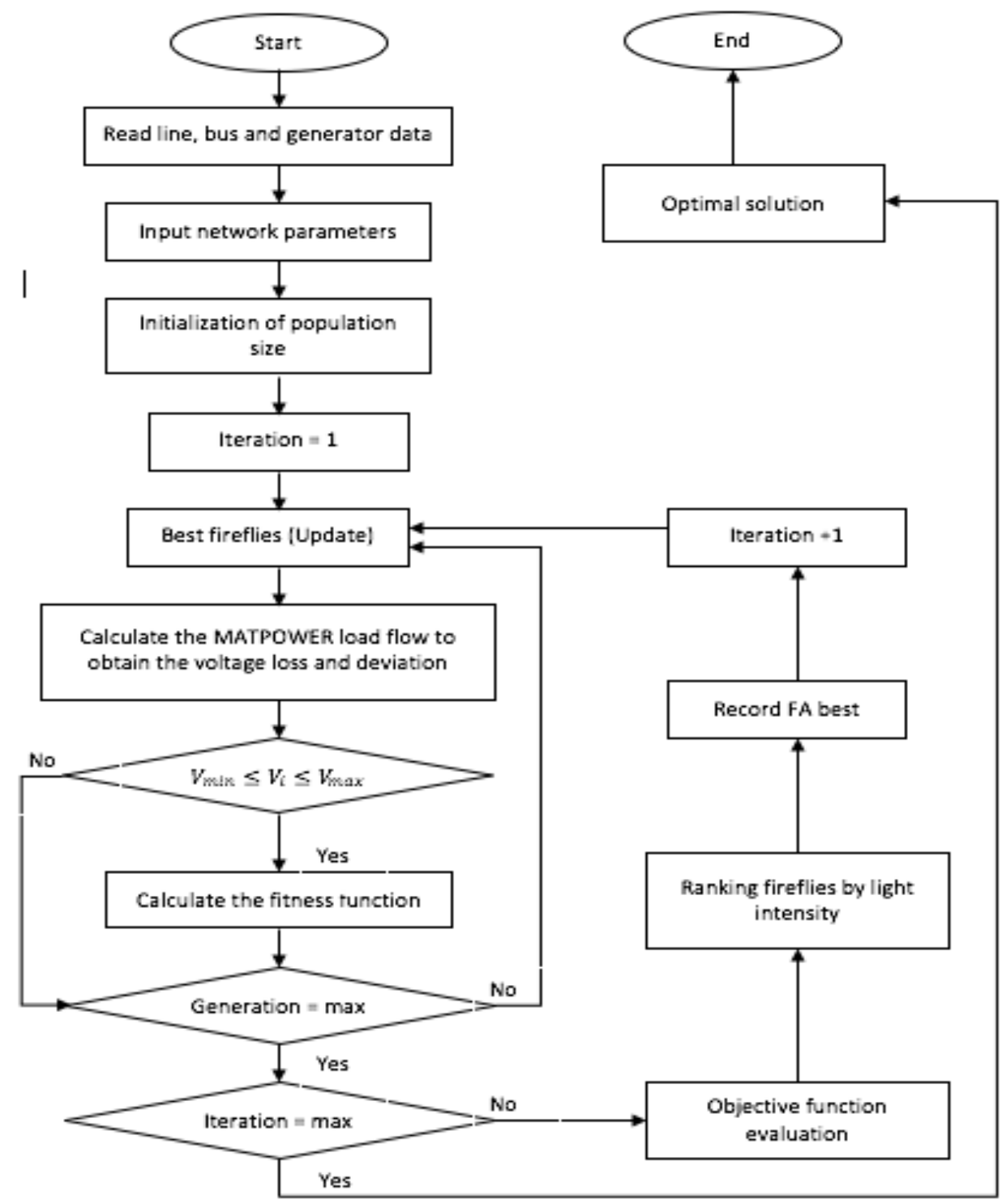

Figure 1. Flowchart of the ideal settings of voltage control with DGs using Firefly Algorithm [24]

The specific steps for implementation of Firefly Algorithm for solving the ideal settings of the coordinated voltage control schemes which are (PFC), (OLTC) and power curtailment are explained as follows [25]:

a) Input the system information such as bus, line and generator data. Initialize the parameters and population.

b) Randomly create the initial positions of distributed generations (DGs) within possible solution combination.

c) Insert the Firefly Algorithm considering the following parameters such as number of fireflies = 50; number of dimension $=6$; maximum iteration $=1000$; alpha $=0.25$; gamma $=$ delta $=1$. These values of alpha, gamma and delta are used in equation stated below for update the movement among all the fireflies.

$$
x_{i}=x_{i}+\beta_{0} * \exp \left(-\gamma r_{i j}^{2}\right) *\left(x_{j}-x_{i}\right)+\alpha *\left(\operatorname{rand}-\frac{1}{2}\right)
$$

d) Calculate the power loss and voltage deviation by running the MATPOWER load flow

e) Check for bus voltage magnitude constraint using (5). If the boundary is exceeded, repeat step 4.

f) Calculate the fitness function using (1). 
g) Update the bestBrigthness and bestFireflies as an objective function for determining the optimal setting problems.

h) Check the light intensity between firefly $i$ and firefly $j$. If the limit is exceeded, continue the step by updating the movement of fireflies for finding the best firefly among of the fireflies. These best firefly position represent the parameters for OLTC, PFC and generation curtailment. The steps will repeat until the maximum population size is reached.

i) The process of optimization is repeated starting from step 4 until the stopping criteria is reached to the maximum so as to obtain the best solution.

\section{SIMULATION RESULTS}

The simulation was done by utilizing the IEEE 13-bus distribution test system. The location of distributed generations (DGs) are set at buses numbers 645 and 684. The locations of DGs are chosen because of bus no 645 and bus 684 have recorded the weakest bus compared to other buses. The load flow data was simulated on MATLAB software. The one line diagram of the IEEE 13-bus distribution network is shown in Figure 2. In this research work of finding the ideal settings, the number of distributed generation units connected in the network is 2. The Firefly Algorithm (FA) method is applied and compared with the BSA method for finding the ideal settings of the coordinated voltage control settings of the IEEE 13-bus distribution network.

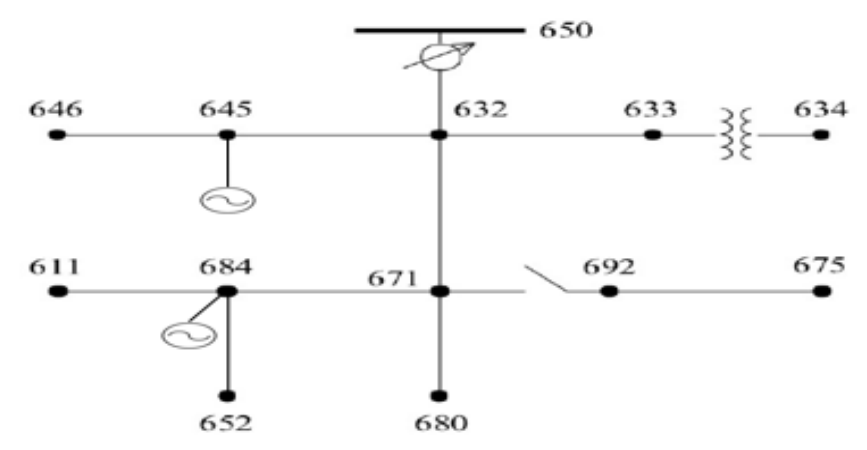

Figure 2. Two DGs connected in the IEEE 13-bus distribution networks

To ensure there is no effect on the voltage profile and losses in the networks, no connection of distributed generation is done at the base case system. Only one DG unit is connected to the selected bus which are at bus 645 or bus 684 at a time. In this paper, there are 3 types of cases that have been tested and the FA and BSA optimization method were coded. These optimizations coded is simulated on the MATLAB software. The three cases are explained as follows:

a. Two DGs with total generation of $1 \mathrm{MW}$ are placed in the test system

b. Two DGs with total generation of $2 \mathrm{MW}$ are placed in the test system

c. Two DGs with total generation of $3 \mathrm{MW}$ are placed in the test system

The objective of determining the voltage deviation, system losses and the ideal values of the coordinated voltage control settings which include PFC, OLTC and generation curtailment are recorded and compared for both the optimization method applied.

Table 1 shows the overall optimization results where the values obtained is referred to the power factor, on-load tap charger and the generation percentages to be curtailed in the distribution networks. Data in Table 1 for the first case study shows that the settings of tap for FA methods are 1.0299 and 0.9945, whereas tap settings for BSA methods are 1.0257 and 0.9830 per unit. Next, the power factor settings for FA are 0.9063 and 0.9284 meanwhile the settings of power factor for BSA are 0.9015 and 0.9146 . The sum of the generation percentages to be curtailed using FA is $26 \%$ and $23 \%$ using BSA. Results for the second case study showed that the tap settings using FA methods are 1.0146 and 1.0097 while BSA recorded values of 1.0289 and 1.0135. The power factor settings using FA are 0.9168 and 0.9397 whereas the values recorded of using BSA are 0.9132 and 0.9147 . The total percentage to be curtailed using FA is $34 \%$ while the percentage recorded using BSA is 29\%. The third case study also displays consistencies in the achieved results. The settings of tap using FA are recorded at 0.9987 and 1.0281 while the ideal tap settings using BSA methods are recorded at 1.0300 and 1.0300 . The power factor settings obtained using FA, which are 0.9220 
and 0.9078 compared to BSA method which are obtained the values of 0.9174 and 0.9009 . For FA method, the total generation percentages to be curtailed is recorded at $28 \%$ while BSA method is recorded at $24 \%$.

Table 1. Optimization Results of FA and BSA for 2 DGs of the IEEE 13-bus distribution system

\begin{tabular}{ccccccc}
\hline & \multicolumn{2}{c}{$1 \mathrm{MW}$} & \multicolumn{2}{c}{ 2MW } & \multicolumn{2}{c}{ 3MW } \\
& FA & BSA & FA & BSA & FA & BSA \\
\hline Best Fitness & 0.6627 & 0.6626 & 0.6239 & 0.6234 & 0.4277 & 0.4275 \\
Tap DG1 & 1.0299 & 1.0257 & 1.0146 & 1.0289 & 0.9987 & 1.0300 \\
Tap DG2 & 0.9945 & 0.9830 & 1.0097 & 1.0135 & 1.0281 & 1.0300 \\
Pf DG1 & 0.9063 & 0.9015 & 0.9168 & 0.9132 & 0.9220 & 0.9174 \\
Pf DG2 & 0.9284 & 0.9146 & 0.9397 & 0.9147 & 0.9078 & 0.9009 \\
Pcurt DG1 & $14.9 \%$ & $15.3 \%$ & $17.11 \%$ & $19.01 \%$ & $17.98 \%$ & $19.56 \%$ \\
Pcurt DG2 & $11.64 \%$ & $8.05 \%$ & $16.94 \%$ & $10.27 \%$ & $10.37 \%$ & $5.02 \%$ \\
\hline
\end{tabular}

Based on Figure 3, 4 and 5, the graphs show the convergence characteristics for the three cases with $1 \mathrm{MW}, 2 \mathrm{MW}$ and $3 \mathrm{MW}$ of DGs integrated respectively. The outcome from the simulation showed that the BSA method gives the least fitness value compared to FA method and also it has faster convergence than FA.
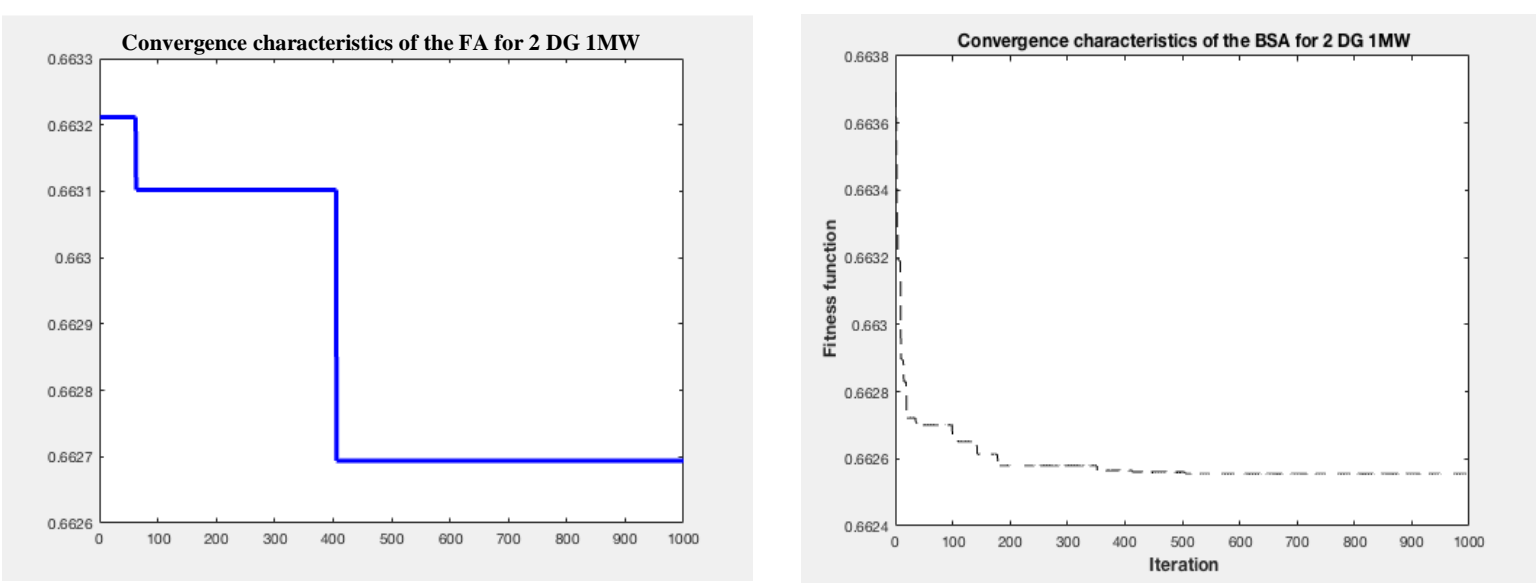

Figure 3. Convergence characteristics of FA and BSA with 2 DGs of 1MW generation in the IEEE 13-bus distribution system
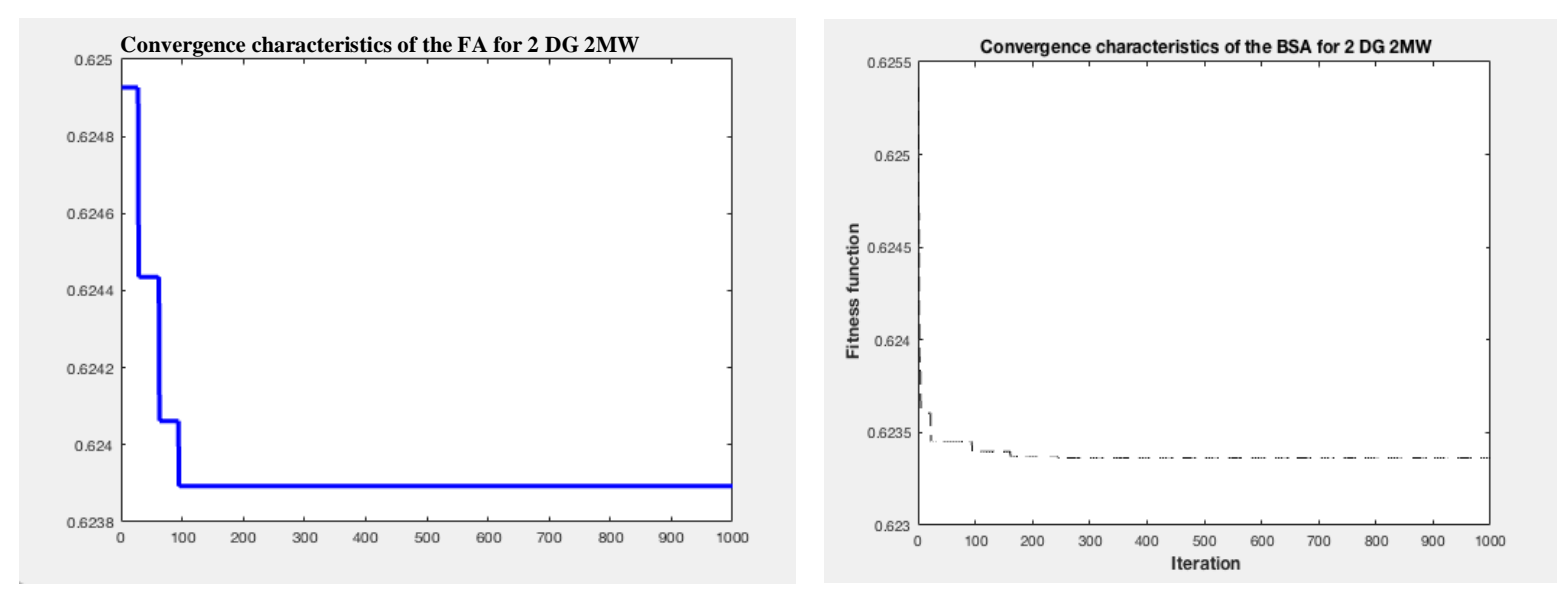

Figure 4. Convergence characteristics of FA and BSA with 2 DGs of 2MW generation in the IEEE 13-bus distribution system 

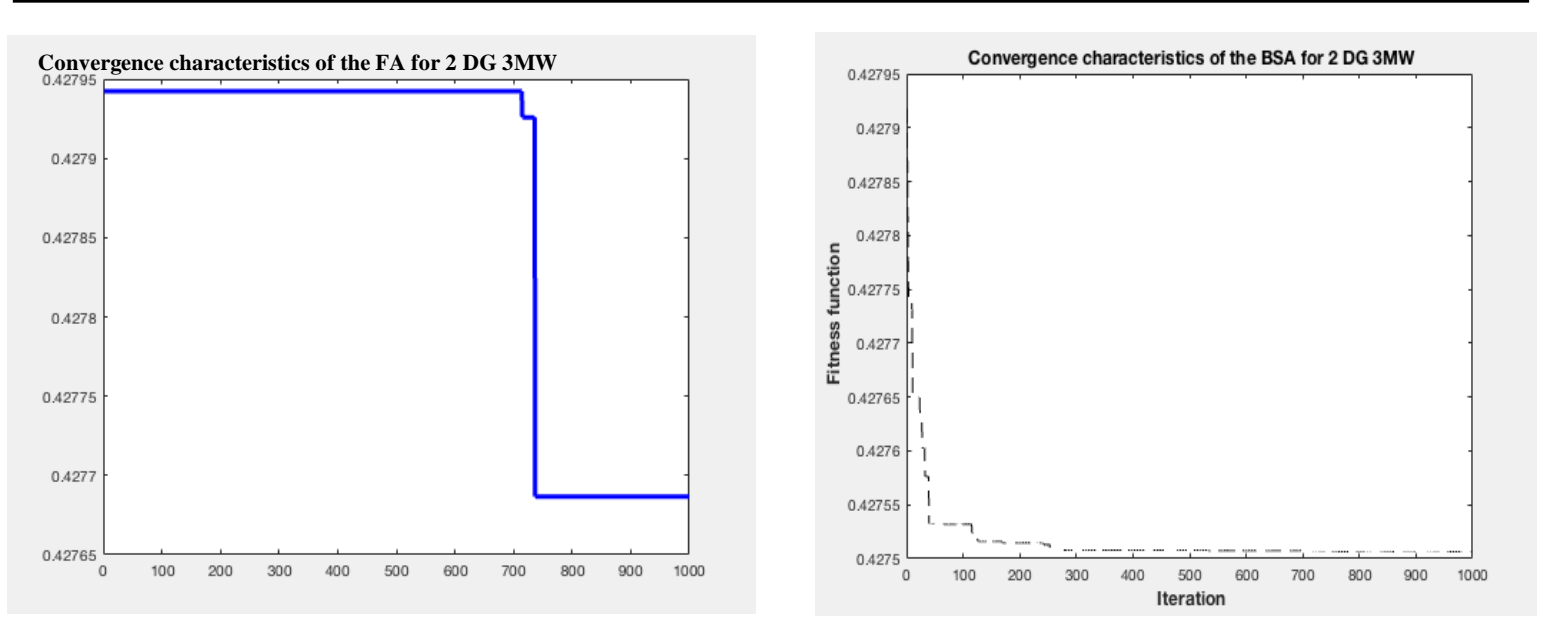

Figure 5. Convergence characteristics of FA and BSA with 2 DGs of 3MW generation in the IEEE 13-bus distribution system

The main objective of this research work is to improve and reduce the power losses and voltage deviation in the distribution systems. Based on Table 2, it clearly explained that after the implementation of the optimization method of FA and BSA, the complete performance of the network shows decreases in power losses and voltage deviation with optimal distributed generation variables settings. Based on Table 2, the power losses for the first case study are reduced to $59.04 \%$ using FA and $60.37 \%$ using BSA methods. The results of power losses for the second case study has reduced to $53.06 \%$ and $61.85 \%$ using FA and BSA, respectively. The third case study has shown a reduction in terms of power losses at $42.68 \%$ and $60.37 \%$ using the optimization methods which are FA and BSA. In terms of voltage deviation, for both optimization methods, the percentage of voltage deviation for all cases has recorded to be improved approximately at $11 \%$. The percentage calculations of power losses and voltage deviation can be calculated by using the following equations:

$$
\begin{aligned}
& P_{\text {loss }}=\frac{P_{\text {loss_basecase }}-P_{\text {loss_optimization }}}{P_{\text {loss_basecase }}} X 100 \% \\
& V D_{\text {improvement }}=\frac{V D_{\text {basecase }}-V D_{\text {optimization }}}{V D_{\text {basecase }}} \times 100 \%
\end{aligned}
$$

Table 2. DG overall results on power loss, voltage deviation, and fitness for all the three cases in IEEE 13-bus distribution networks

\begin{tabular}{ccccc}
\hline DG availability & Optimization Method & Losses (MW) & Voltage deviation (V) & Fitness \\
\hline Base case & - & 0.1012 & 0.9998 & - \\
With 1MW DG & FA & 0.0414 & 0.8923 & 0.6627 \\
& BSA & 0.0401 & 0.8908 & 0.6626 \\
With 2MW DG & FA & 0.0475 & 0.8752 & 0.6239 \\
& BSA & 0.0386 & 0.8719 & 0.6234 \\
With 3MW DG & FA & 0.0578 & 0.8655 & 0.4277 \\
& BSA & 0.0401 & 0.8598 & 0.4275 \\
\hline
\end{tabular}

\section{CONCLUSION}

As a conclusion, this paper proposed a coordinated optimal voltage control method by using two optimization techniques which are Firefly algorithm (FA) and Backtracking Search algorithm (BSA) to determine three different voltage control settings, namely, power factor control, on-load tap charger and generation curtailment. The two optimizations algorithm selected have been implemented on the IEEE 13bus distribution network connected with distributed generations with different values of generation. The results obtained from these two algorithms are compared in terms of the performance of fitness function and convergence. From the results obtained, it has been found that BSA performs better compared to FA in terms of accuracy by giving lower fitness function value and achieving faster convergence rate. In addition, both optimization methods are able to reduce the system losses and also improve voltage deviation in the active 
dispersal network with the ideal settings of PFC, OLTC and generation curtailment. Thus, all the proposed optimization methods have met the objectives of this research work.

\section{ACKNOWLEDGEMENTS}

The authors would like to express their gratitude to Universiti Tenaga Nasional (UNITEN) for providing the funding for this research and acknowledges the UNITEN Internal Grant (UNIIG) Project Code J510050699.

\section{REFERENCES}

[1] P. M. S. Carvalho, et al., "Distributed Reactive Power Generation Control for Voltage Rise Mitigation in Distribution Networks," IEEE trans. Power Syst., vol. 23, pp.766-772, May 2008.

[2] P. H. Nguyen, et al., "Coordination of Voltage Regulation in Active Networks," IEEE, 2008.

[3] Niknam T., et al., "Impact of distributed generation on volt/var control in distribution network," IEEE PowerTech Conference, pp. 1-7, 2003.

[4] K. Tanaka, "Decentralized voltage control in distribution systems by distributed generators," Industrial Electronics 2009. ISIE 2009. IEEE International Symposium on, pp. 554-559, Jul 2009.

[5] Shicheng L., et al., "Reactive power optimization and voltage control using a multi-objective adaptive particle swarm optimization algorithm," China International Conference on Electricity Distribution, pp. 1-7, 2010.

[6] M. A. Azzouz and E. F. El Saadany, "Optimal coordinated volt/var control in active distribution networks," IEEE, 2014.

[7] H. E. Farag, et al., "A Two Ways Communication Based Distributed Control for Voltage Regulation in Smart Distribution Feeders," IEEE Trans. Smart Grid, vol. 3, pp. 271-281, Mar 2012.

[8] K. Liu, et al., "Decentarlized voltage optimization and coordinated method in smart distribution grid," IEEE, 2015.

[9] V. Calderaro, et al., "Reactive power control for improving voltage profiles: A comparison between two decentralized approaches," Electr. Power Syst. Res., vol. 83, pp. 247-254, Feb 2012.

[10] S. Deshmukh, et al., "Voltage/VAR control in distribution networks via reactive power injection through distributed generators," IEEE Trans. Smart Grid, vol. 3, pp. 1226-1234, Sep 2012.

[11] C. Smith, et al., "Improvement in the performance of on-load tap changer transformers operating in series," Power Engineering Society General Meeting 2003 IEEE, vol. 3, pp. 1910, Jul 2003.

[12] P. N. Vovos, et al., "Centralized and distributed voltage control: Impact on distributed generation penetration," IEEE Transactions on Power Systems, vol. 22, Feb 2007.

[13] M. J. Dolan, et al., "Distribution power flow management utilizing an online optimal power flow technique," IEEE Trans. Power. Syst., vol. 27, pp. 790-799, 2012.

[14] Apostolopoulos and T. Vlachos, "Application of the Firefly Algorithm for Solving the Economic Emissions Load Dispatch Problem," International Journal of Industrial Engineering Computations, vol. 1, pp. 1-10, 2010.

[15] H. Broersma, "Application of the Firefly Algorithm for Solving the Economic Emissions Load Dispatch Problem," Hindawi Publishing Corporation, International Journal of Combinatorics, 2011.

[16] X. Yang, "Nature-inspired Metaheuristic Algorithms," Luniver Press, 2008.

[17] Rugthaicharoencheep N., et al., "Network reconfiguration for loss reduction and improved voltage profile in distribution systems with distributed generation using genetic algorithm," 5th Conference of Electrical Engineering Network of Rajamangala University of Technology, pp.1-4, 2013.

[18] A. Sadighmanesh, et al., "Distributed generation unit and capacitor placement for multi-objective optimization," International Journal of Electrical and Computer Engineering (IJECE), vol. 2, pp. 615-620, Oct 2012.

[19] K. I. Tharakan and O. V. G. Swathika, "Optimum coordination of using overcurrent relay using firefly and ant colony optimization algorithm," International Conference on Computing Methodologies and Communication (ICCMC), 2017.

[20] Z. Honarpisheh and K. Paez, "An efficient dorsal hand vein recognition based on firefly algorithm," International Journal of Electrical and Computer Engineering (IJECE), vol. 3, pp. 30-41, Feb 2013.

[21] V. Gupta, et al., "Optimal placement of distributed generators in distribution system using backtracking search optimization for various load models," International Conference on Recent Development in Control, Auromation and Power Engineering (RDCAPE), 2015.

[22] P. Civicioglu, "Backtracking Search Optimization Algorithm for numerical optimization problems," Appl. Math. Comput., vol. 219, pp. 8121-8144, 2013.

[23] W. L. Ai, et al., "Optimal Battery Placement in Photovoltaic Based Distributed Generation using Binary Firefly Algorithm for Voltage Rise Mitigation," IEEE International Conference Power and Energy (PECON), 2014.

[24] K. Nadhir, et al., "Firefly Algorithm for Optimal Allocation and Sizing of Distributed Generation in Radial Distribution System for Loss Minimization," IEEE, 2013.

[25] S. M. Farahani, et al., "A Gaussian Firefly Algorithm," International Journal of Machine Learning and Computing, vol. 1, Dec 2011. 


\section{BIOGRAPHIES OF AUTHORS}

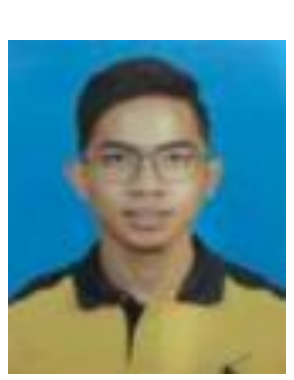

Muhamad Najib bin Kamarudin was born on $12^{\text {th }}$ April 1995 at Assunta Hospital, Petaling Jaya, Malaysia. He is currently living in Bandar Baru Bangi, Selangor. He recently earned his Bachelor's degree in Electrical Power Engineering from Universiti Tenaga Nasional (UNITEN) in 2018. His current research interests includes power quality and optimization in power system analysis.

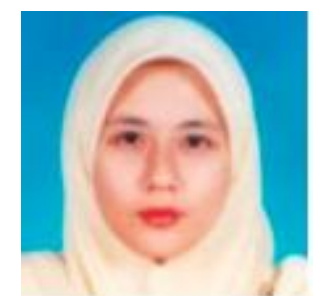

Tengku Juhana Tengku Hashim was born in Kuantan, Pahang, Malaysia in May 1979. She received her B. Eng in Electrical Power Engineering in 2002 and Masters in Electrical Engineering in 2004 from Universiti Tenaga Nasional (UNITEN), Selangor, Malaysia. She obtained her $\mathrm{PhD}$ in Electrical, Electronics and Systems Engineering from Universiti Kebangsaan Malaysia (UKM), Bangi Malaysia in 2014 specializing in the area of optimization of voltage control methods in an active distribution system. She is currently a Senior Lecturer with the Department of Electrical Power Engineering, Universiti Tenaga Nasional (UNITEN). Her current research interests includes power quality and optimization in power system analysis. 